\title{
Organizational Stressors \& Occupational Stress of Software Professionals in India
}

\author{
Dr. Gautami S. ${ }^{1} *$, Dr. T. Anupama ${ }^{2}$
}

\section{ABSTRACT}

In the current lifestyle of utmost complexities, the stress level is raising at a phenomenal rate. The factors that contribute to stress not only differ between cultures, but also within the culture itself, from a sophisticated to a normal class family, the ultimate necessity is the job, may it be a business or a salaried job.

This research work is an analytical, empirical study based on survey of IT professionals in India. The sample was drawn from the various IT hubs in India to make it more representative of the IT professional's population. Through the pre-tested questionnaire used in the survey, data were generated on the respondents' demographics, their perceived organizational stressors like Inter Role Distance, Role Stagnation, Role Expectation Conflict, Role Erosion, Role Overload, Role Isolation, Personal Inadequacy, Self-Role Distance, Role Ambiguity, Role Inadequacy.

The findings of this study would contribute significantly in better understanding of the stress in IT sector by the academicians and the practitioners. Finally, this study enriches the literature on stress management with respect to the sunshine industry of India.

Key words: Demographics, organizational stressors, Inter Role Distance, Role Stagnation, Role Expectation Conflict, Role Erosion, Role Overload, Role Isolation, Personal Inadequacy, SelfRole Distance, Role Ambiguity, Role Inadequacy.

Keywords: Organization, Stressors, Occupational Stress, Software professionals, India

The organizational stressors are a major source of satisfaction as well as frustration for the employees. Certain characteristics or inadequacies of job role have been noted as prominent source of occupational stress. The concept of role is the key concept in understanding the integration of the occupation in a system. Every organization is composed of a number of positions and specific roles associated with these positions. Position or office is essentially a relational concept, defining one position in terms of its relationship to other and to the system as a whole.

\footnotetext{
${ }^{1}$ Associate Professor, Department of Management Studies, S. V. Colleges, Tirupati

2 Assistant Professor, Department of Management Studies, S. V. Colleges, Tirupati

*Responding Author

(C) 2016 I S Gautami, T Anupama; licensee IJIP. This is an Open Access Research distributed under the terms of the Creative Commons Attribution License (http://creativecommons.org/licenses/by/2.0), which permits unrestricted use, distribution, and reproduction in any Medium, provided the original work is properly cited.
} 
Normally, performance of a role satisfies various needs of its occupant. But sometimes it becomes a potential source of stress too for the role-occupant. The problem a role-occupant faces today is that of managing the complex structure of roles by achieving an integration of one's self with the system of other roles as well as integration of various roles a person may be occupying. In the present study, the organizational stressors were examined based on the Occupational Role Stress Scale (ORS) developed by Pareek (1993). The responses against each factor was collected by using five statements on Likert's 1 - 5 scale with each response being anchored to numerical value assigned to it.

Thus, calculated mean value of the organizational stressors ranges from a minimum of 1 (Strongly disagree) and a maximum of 5 (Strongly agree). Each factor was examined with five statements. The following section deals with the frequency tables of all the ten stressors of occupational stress.

\section{RESEARCH METHODOLOGY}

\section{Statement of the problem}

The problem of stress at work place is the key issue to be addressed immediately in IT sector which is at alarming stage so that the prime stressors are identified and action plans are suggested in order to minimize the stress levels and make the work place free from stress.

\section{Significance of the study}

The inevitable phenomenon of stress is wide spread in all most all working professionals and very high especially for IT (Information Technology) professionals. The study aims in analysing how the IT professionals are prone to Stress, the impact of stress on job satisfaction and how they cope with the stress faced.

\section{Research design}

Research design outlines the procedures for obtaining the information needed to structure or solve research problems. It gives a framework or blueprint for the study, suggesting the type of data to get or observations to make, how to analyse them, and the possible conclusions that can be drawn from the analysis. Continuing the legacy of earlier research works, the research design of the present study considered organizational stressors as key areas of research to make more comprehensive study in the area of stress management that has been identified as a gap in the research studies reviewed.

\section{OBJECTIVES}

The present study was designed to analyze the various factors influencing occupational stress of information technology professionals in India, with following specific objectives:-

1. To identify the sources or causes of occupational stress in the IT industry.

2. To suggest suitable measures for reducing occupational stress to the IT companies. 


\section{HYPOTHESIS TESTING}

H01: There are no significant relationship between organizational stressors and occupational stress levels

The core objective of the study is to empirically investigate the relationship between the organizational stressors considered in the present study and the occupational stress levels. The linear regression analysis was performed to examine the statistical significant relationship between the stressors considered and stress levels by 'Enter' method. Regression is not just one technique but a family of techniques that can be used to explore the relationship between one continuous dependent variable and a number of independent variables or predictors (Pallant, 2007). Regression is based on correlation, but allows a more sophisticated exploration of the interrelationship among a set of variables.

Table 1 shows that $45 \%$ of variance in occupational stress level is explained by the model, which is quite a respectable result when compared with some of the previous studies. The table also displays the "Durbin-Watson test for autocorrelation" which is a statistic that indicates the likelihood that the deviation (error) values for the regression.

Table 1 Regression Model Testing between Organizational Stressors and Occupational Stress - Model Summary ${ }^{b}$

\begin{tabular}{|l|l|l|l|l|l|}
\hline \multicolumn{2}{|c|}{ Model Summary } \\
\hline Model & R & R Square & Adjusted R Square & Std. Error of the Estimate & Durbin-Watson \\
\hline 1 & $.670^{\mathrm{a}}$ & .450 & .438 & .35086 & 1.799 \\
\hline
\end{tabular}

a. $\quad$ Predictors: (Constant), RIN, RE, IRD, PI, RS, RI, REC, RA, SRD, RO b. Dependent Variable:

\section{Overall Stress}

The Durbin-Watson statistic is always between 0 and 4 . A value of ' 2 ' means that there is no autocorrelation in the sample. Values approaching ' 0 ' indicate positive autocorrelation and values toward ' 4 ' indicate negative autocorrelation. The Durbin-Watson value is close to ' 2 ' which represents no autocorrelation which means the values are independent.

Table 2, Regression Model Testing - ANOVA Results on Occupational Stress

\begin{tabular}{|l|l|l|l|l|l|l|}
\hline \multicolumn{2}{|l|}{ ANOVA $^{\text {a }}$} & Sum of Squares & & \\
\multicolumn{2}{|c|}{ Model } & & df & Mean Square & F & Sig. \\
\hline \multirow{3}{*}{1} & Regression & 47.343 & 10 & 4.734 & 38.459 & $\mathbf{. 0 0 0}^{\mathbf{b}}$ \\
\cline { 2 - 8 } & Residual & 57.980 & 471 & .123 & & \\
\cline { 2 - 8 } & Total & 105.324 & 481 & & & \\
\hline
\end{tabular}

a. Dependent Variable: Overall Stress

b. Predictors: (Constant), RIN, RE, IRD, PI, RS, RI, REC, RA, SRD, RO 
Table 2 displays the ANOVA Test results of the model tested by using the linear regression analysis. The analysis of variance conducted by considering occupational stress level as dependent variable (a) and all the organizational stressors considered as independent variable (b) displayed significance value less than $0.000(\mathrm{p}<0.05)$ with $\mathrm{F}$ value as 38.459 . This shows that the model displayed statistical significant relationship between the predictors' i.e. independent variables and the occupational stress level i.e. dependent variable.

Table 3, Model Testing - t test Results on Occupational Stress

\begin{tabular}{|c|c|c|c|c|c|c|}
\hline \multicolumn{7}{|c|}{ Coefficients $^{\mathbf{a}}$} \\
\hline \multirow{2}{*}{\multicolumn{2}{|c|}{ Model }} & \multicolumn{2}{|c|}{$\begin{array}{l}\text { Unstandardized } \\
\text { Coefficients }\end{array}$} & $\begin{array}{l}\text { Standardized } \\
\text { Coefficients }\end{array}$ & \multirow[b]{2}{*}{$\mathrm{t}$} & \multirow[b]{2}{*}{ Sig. } \\
\hline & & & Std. Error & Beta & & \\
\hline \multirow{11}{*}{1} & (Constant) & 2.475 & .095 & & 26.115 & .000 \\
\hline & IRD & .354 & .035 & .516 & 10.217 & .000 \\
\hline & RS & -.278 & .041 & -.441 & -6.751 & .000 \\
\hline & REC & -.268 & .048 & -.407 & -5.580 & .000 \\
\hline & $\mathrm{RE}$ & -.080 & .041 & -.128 & -1.976 & .049 \\
\hline & RO & -.234 & .062 & -.319 & -3.764 & .000 \\
\hline & RI & .233 & .053 & .318 & 4.420 & .000 \\
\hline & PI & .183 & .040 & .294 & 4.564 & .000 \\
\hline & SRD & .306 & .043 & .596 & 7.074 & .000 \\
\hline & RA & .272 & .037 & .508 & 7.399 & .000 \\
\hline & RIN & -.258 & .062 & -.389 & -4.153 & .000 \\
\hline a. & \multicolumn{3}{|c|}{ Scale } & \multirow{2}{*}{\begin{tabular}{|l|} 
No of Items \\
5
\end{tabular}} & Mean & S.D. \\
\hline 1 & \multicolumn{3}{|c|}{ Inter Role Distance } & & 2.38 & 0.682 \\
\hline 2 & \multicolumn{3}{|c|}{ Role Stagnation } & 5 & 2.53 & 0.742 \\
\hline 3 & \multicolumn{3}{|c|}{ Role Expectation Conflict } & 5 & 2.45 & 0.710 \\
\hline 4 & \multicolumn{3}{|c|}{ Role Erosion } & 5 & 2.68 & 0.743 \\
\hline 5 & \multicolumn{3}{|c|}{ Role Overload } & 5 & 2.39 & 0.637 \\
\hline 6 & \multicolumn{3}{|c|}{ Role Isolation } & 5 & 2.29 & 0.638 \\
\hline 7 & \multicolumn{3}{|c|}{ Personal Inadequacy } & 5 & 2.69 & 0.749 \\
\hline 8 & \multicolumn{3}{|c|}{ Self-Role Distance } & 5 & 2.36 & 0.911 \\
\hline 9 & \multicolumn{3}{|c|}{ Role Ambiguity } & 5 & 2.23 & 0.873 \\
\hline 10 & \multicolumn{3}{|c|}{ Role Inadequacy } & 5 & 2.14 & 0.704 \\
\hline \multicolumn{5}{|c|}{ Overall Score for Organizational Stressors } & 2.41 & 0.577 \\
\hline
\end{tabular}


Table 5 : Hypothesized Outcomes of Occupational Stress

\begin{tabular}{|l|l|l|}
\hline Hypotheses & Statement & Result \\
\hline $\mathbf{H} 01$ & $\begin{array}{l}\text { There are no significant relationship between } \\
\text { Organizational stressors and Occupational } \\
\text { stress }\end{array}$ & Rejected \\
\hline
\end{tabular}

\section{FINDINGS OF THE STUDY}

In line with the objectives and hypotheses tested, this discussion will cover the major findings of the present study:

\section{Organizational Stressors}

The present study has considered ten organizational stressors to examine. From the analysis made, it can be found that all the organisational stressors were recorded as having low impact on the sample IT professionals. Among the selected organizational stressors, personal inadequacy (mean=2.69) and role erosion (mean=2.68) found to be having high scores. The overall mean of total organizational stressors was also low (mean=2.41). These low values might be because of the biased information given by the sample respondents. The organizational stressors found to be having significant impact on the occupational stress of the respondents. All the stressors selected in the present study have exhibited $45 \%$ of variance in the occupational stress of the IT professionals.

\section{SUMMARY}

The hypotheses framed relating organizational stressors and occupational stress were tested using appropriate statistical tools. The study found no significant relationship of gender and marital status on occupational stress. By conducting $\mathrm{z}$ test and analysis of variance, the study found age, education, experience, working hours and income having significant relationship with occupational stress. By employing linear regression model testing, it is found that $45 \%$ of variance in occupational stress can be explained by the ten organizational stressors considered in the present study. The results of the hypotheses were tabulated in the above table.

\section{REFERENCES:}

\section{Text Books}

Appley, T. and Trumbull, R. (1967), "Psychological Stress”, Century and Crofts, New York: Appleton

Buunk, B. P., de Jonge, J., Ybema, J. F., \& de Wolff, C. J. (1991). "Psychosocial Aspects of Occupational Stress”, In P. J. D. Drenth, H. Thierry \& C. J. de Wolff (Eds.), Handbook of Work and Organizational Psychology, pp. 145 - 182.

Caplan, R.D., Cobb, S., French, J.R., Harrison, R.D. \& Pinneau, S.R. (1975), “Job Demands and Worker Health: Main effects and occupational differences”, Washington: U.S. Government Printing Office. 


\section{Organizational Stressors \& Occupational Stress of Software Professionals in India}

\section{Articles}

Alexandros, S. G. A., Marilyn J. D., \& Cary L. C. (2003), "Occupational Stress, Job Satisfaction and Health State in Male and Female Junior Hospital Doctors in Greece", Journal of Managerial Psychology, Vol. 18, No. 6, pp. 592 - 621.

Andrew J. Noblet \& Sandra M. Gifford (2002), "The Sources of Stress Experienced by Professional Australian Footballers”, Journal of Applied Sport Psychology, Vol. 14, pp. $1-13$.

Aniza, I. M. H.; Malini, R. M. \& Khalib, L. MPH (2010), “A Study on Organizational Factors That Influence Job Stress Among Medical Laboratory Technologists in Klang Valley Hospitals”, Med J Malaysia, Vol. 65, No. 2, pp. 103 - 107.

Christian, Profaina K., (2011), “A study of life events, life strains and coping behaviour in psychologically distressed and non-distressed college students”, Thesis submitted to Saurashtra University.

Accessed from http://etheses.saurashtrauniversity.edu on 18/06/2013

Coetzer, W. J. and Rothmann, S. (2006), "Occupational stress of employees in insurance company”, South African Journal of Business Management, Vol. 37, No. 3, pp. 29 - 39

How to cite this article: S Gautami, T Anupama (2016), Organizational Stressors \& Occupational Stress of Software Professionals in India, International Journal of Indian Psychology, Volume 3, Issue 3, No. 8, DIP: 18.01.143/20160303, ISBN: 978-1-365-12176-0 